\title{
An EP2 Agonist Facilitates NMDA-Induced Outward Currents and Inhibits Dendritic Beading through Activation of BK Channels in Mouse Cortical Neurons
}

\author{
Yoshinori Hayashi, ${ }^{1}$ Saori Morinaga, ${ }^{1,2}$ Xia Liu, ${ }^{1,3}$ Jing Zhang, ${ }^{1}$ Zhou Wu, \\ Takeshi Yokoyama, ${ }^{2}$ and Hiroshi Nakanishi ${ }^{1}$ \\ ${ }^{1}$ Department of Aging Science and Pharmacology, Faculty of Dental Sciences, Kyushu University, Fukuoka 812-8582, Japan \\ ${ }^{2}$ Department of Dental Anesthesiology, Faculty of Dental Sciences, Kyushu University, Fukuoka 812-8582, Japan \\ ${ }^{3}$ Institute for Metabolic and Neuropsychiatric Disorders, Binzhou Medical University, Binzhou 256603, China
}

Correspondence should be addressed to Yoshinori Hayashi; yoshinor@dent.kyushu-u.ac.jp

and Hiroshi Nakanishi; nakan@dent.kyushu-u.ac.jp

Received 26 February 2016; Revised 19 April 2016; Accepted 4 May 2016

Academic Editor: Hermann Gram

Copyright (C) 2016 Yoshinori Hayashi et al. This is an open access article distributed under the Creative Commons Attribution License, which permits unrestricted use, distribution, and reproduction in any medium, provided the original work is properly cited.

\begin{abstract}
Prostaglandin $\mathrm{E}_{2}\left(\mathrm{PGE}_{2}\right)$, a major metabolite of arachidonic acid produced by cyclooxygenase pathways, exerts its bioactive responses by activating four E-prostanoid receptor subtypes, EP1, EP2, EP3, and EP4. $\mathrm{PGE}_{2}$ enables modulating $N$-methyl-Daspartate (NMDA) receptor-mediated responses. However, the effect of E-prostanoid receptor agonists on large-conductance $\mathrm{Ca}^{2+}$ activated $\mathrm{K}^{+}(\mathrm{BK})$ channels, which are functionally coupled with NMDA receptors, remains unclear. Here, we showed that EP2 receptor-mediated signaling pathways increased NMDA-induced outward currents $\left(I_{\text {NMDA-OUT }}\right)$, which are associated with the BK channel activation. Patch-clamp recordings from the acutely dissociated mouse cortical neurons revealed that an EP2 receptor agonist activated $I_{\mathrm{NMDA}-\mathrm{OUT}}$, whereas an EP3 receptor agonist reduced it. Agonists of EP1 or EP4 receptors showed no significant effects on $I_{\mathrm{NMDA} \text {-OUT }}$. A direct perfusion of $3,5^{\prime}$-cyclic adenosine monophosphate (cAMP) through the patch pipette facilitated $I_{\text {NMDA-OUT }}$, which was abolished by the presence of protein kinase A (PKA) inhibitor. Furthermore, facilitation of $I_{\text {NMDA-OUT }}$ caused by an EP2 receptor agonist was significantly suppressed by PKA inhibitor. Finally, the activation of BK channels through EP2 receptors facilitated the recovery phase of NMDA-induced dendritic beading in the primary cultured cortical neurons. These results suggest that a direct activation of BK channels by EP2 receptor-mediated signaling pathways plays neuroprotective roles in cortical neurons.
\end{abstract}

\section{Backgrounds}

We have previously reported that interleukin-1 $\beta$ (IL-1 $\beta$ ) increases neuronal excitability via the inhibition of largeconductance $\mathrm{Ca}^{2+}$-induced $\mathrm{K}^{+}$channels (BK) activated by $\mathrm{Ca}^{2+}$ influx through both NMDA receptors (NMDARs) and voltage-dependent $\mathrm{Ca}^{2+}$ channels (VDCC) in the dissociated hippocampal neurons $[1,2]$. The inhibitory effect of IL$1 \beta$ on the amplitude of NMDA-induced outward currents $\left(I_{\text {NMDA-OUT }}\right)$, which is mediated by BK channel activation, is largely mediated by phosphorylation of p38 mitogenactivated protein kinase (MAPK) [2]. It is considered that active p38 MAPK directly phosphorylates BK channels to decrease the amplitude of $I_{\text {NMDA-OUT }}$. On the other hand, it has been reported that prostaglandin $\mathrm{E}_{2}\left(\mathrm{PGE}_{2}\right)$ potentiates the amplitude of $I_{\mathrm{NMDA} \text {-OUT }}$ in the dissociated preoptic neurons [3]. However, the precise intracellular mechanism underlying the effects of $\mathrm{PGE}_{2}$ on $\mathrm{BK}$ channels activated by $\mathrm{Ca}^{2+}$ influx through NMDARs still remains to be determined.

$\mathrm{PGE}_{2}$, a major metabolite of arachidonic acid produced by cyclooxygenase pathways, can bind to four E-prostanoid receptor subtypes, EP1, EP2, EP3, and EP4. The EP1 receptors couple to Gq and unidentified G protein. The EP2 and EP4 receptors couple positively to Gs to increase cAMP, whereas 
the EP3 receptors couple negatively to cAMP via Gi [4]. $\mathrm{PGE}_{2}$ has a potential therapeutic role for the neurotoxicity through EP2 receptors. In addition, the selective EP2 receptor activation leads to a protection of neurons against NMDARmediated excitotoxicity and oxygen-glucose deprivationinduced anoxia in the hippocampal neurons [5-7], whereas the genetic deletion of EP2 receptors exacerbates the brain damage after infarction [8]. At present, it is considered that EP2 receptors induce neuroprotection through the activation of cAMP-protein kinase A (PKA) pathway and the subsequent activation of cAMP-responsive element binding protein (CREB), which facilitates the neuronal survival [9]. In fact, PKA inhibitors abrogate the EP2 receptor-mediated neuroprotection [5].

In the present study, we showed that $\mathrm{PGE}_{2}$ enhanced $I_{\mathrm{NMDA}-\mathrm{OUT}}$ through the activation of EP2 receptors in mouse cortical neurons. The activation of $\mathrm{cAMP} / \mathrm{PKA}$ signaling pathway was involved in the EP2 receptor agonist-induced potentiation of $I_{\text {NMDA-OUT }}$. Furthermore, an EP2 receptor agonist facilitated the recovery from NMDA-induced dendritic beading.

\section{Materials and Methods}

2.1. Animals. The experimental protocol was approved by the Animal Research Committee of Kyushu University. All efforts were made to minimize animal suffering and to reduce the number of animals used. Embryonic day 19 mouse pups and 3-week-old male C57BL/6 mice were used for electrophysiology and immunohistochemistry. The mice were maintained on a $12 \mathrm{hr}$ light/dark cycle (light on at 8:00 $\mathrm{AM}$ ) under conditions of $22-25^{\circ} \mathrm{C}$ ambient temperature with food and water ad libitum.

2.2. Compounds. KT5720 (a specific PKA inhibitor), cAMP, NMDA, and paxilline (a specific BK channel blocker) were purchased from Sigma. Butaprost (an EP2 receptor agonist) and TG6-10-1 (an EP2 receptor antagonist) were purchased from Cayman and Millipore, respectively. The concentrations of EP2 agonists/antagonists were determined according to the paper as previously described $[5,10]$. Synthesized selective agonists of EP1 receptor (ONO-DI-004), EP2 receptor (ONO-AE1-259), EP3 receptor (ONO-AE-248), and EP4 receptor (ONO-AE1-329) were kindly provided from Ono Pharmaceuticals.

2.3. Cortical Slice Preparation and Mechanical Dissociation of Cortical Neurons. The C57BL/6 mice (3 weeks old) were anesthetized with pentobarbital sodium ( $200 \mathrm{mg} / \mathrm{kg}$ i.p.) and then decapitated. The cortical slice preparations with a thickness of $375 \mu \mathrm{m}$ were made using a microslicer (VT1000S; Leica, Nussloch, Germany). The slices were kept in the incubation medium saturated with $95 \% \mathrm{O}_{2}-5 \% \mathrm{CO}_{2}$ at room temperature $\left(21-24^{\circ} \mathrm{C}\right)$ for $\geq 1 \mathrm{hr}$ before mechanical dissociation. The incubation medium contained (mM) $124 \mathrm{NaCl}, 3$ $\mathrm{KCl}, 1.5 \mathrm{KH}_{2} \mathrm{PO}_{4}, 24 \mathrm{NaHCO}_{3}, 2.4 \mathrm{CaCl}_{2}, 1 \mathrm{MgCl}_{2}$, and 10 glucose. Mechanical dissociation was accomplished using a custom-built vibration device and a fire-polished glass pipette as previously described [11].

2.4. Patch-Clamp Recording. Voltage-clamp recordings from mechanically dissociated cortical neurons were carried out using perforated whole-cell patch-clamp technique as previously described [1]. Amphotericin B $(260 \mu \mathrm{g} / \mathrm{mL})$ was added to pipette solution (the pipette solution contained (mM) 70 K-methanesulfonate, $10 \mathrm{KCl}$, and $10 \mathrm{HEPES}$ ). The external solution contained (in $\mathrm{mM}$ ) $150 \mathrm{NaCl}, 5 \mathrm{KCl}, 2 \mathrm{CaCl}_{2}, 10$ HEPES, and 10 glucose ( $\mathrm{pH} 7.4$ ). For the whole-cell recordings, cAMP or KT 5720 was added to pipette solution. NMDA was applied for $20 \mathrm{sec}$ at an interval of $5 \mathrm{~min}$ [11]. Agonists of EP1-EP4 receptors were simultaneously applied with NMDA. The holding potential was maintained at $-40 \mathrm{mV}$ throughout the voltage-clamp experiments.

2.5. Primary Cultured Cortical Neurons. Cortices were obtained from embryonic day 19 (E19) mouse pups and dissociated with $90 \mathrm{U}$ papain (Worthington Biochemical Corp., Lakewood, NJ, USA) in Hank's balanced salts solution (HBSS) (Gibco, Grand Island, NY USA) containing $10 \mathrm{mM} \mathrm{N}$-[2-hydroxyethyl]piperazine- $\mathrm{N}^{\prime}$-[2-ethanesulfonic acid] (HEPES) ( $\mathrm{pH} 7.5$ ). Cortices were seeded onto polyethyleneimine (PEI) coated $13 \phi$ cover glass (Matsunami) with attachment medium. Medium was replaced into maintenance medium on the following day. Attachment medium was minimum essential medium (MEM) (Gibco) containing 10\% horse serum, $450 \mathrm{mg} / \mathrm{mL}$ glucose, $1 \%$ penicillin/streptomycin, and $1 \%$ sodium pyruvate. Maintenance medium was neurobasal medium containing $2 \% \mathrm{~B}$ 27 (Gibco), 1\% glutamine, and 1\% penicillin/streptomycin. Cortical neurons were used for the experiment on 10 days in vitro (DIV).

2.6. Immunohistochemistry. NMDA $(30 \mu \mathrm{M})$ was diluted with Locke's solution and applied to cortical neurons on 10 $\mathrm{DIV}$ at $37^{\circ} \mathrm{C}$ for 10 minutes. Locke's solution contained (mM) $154 \mathrm{NaCl}, 5.6 \mathrm{KCl}, 2.3 \mathrm{CaCl}_{2}, 1 \mathrm{MgCl}_{2}, 3.6 \mathrm{NaHCO}_{3}, 5 \mathrm{HEPES}$, and 10 glucose ( $\mathrm{pH}$ 7.2). NMDA exposure was terminated by fixation with $4 \%$ paraformaldehyde at $4^{\circ} \mathrm{C}$ for $1 \mathrm{hr}$. Cortical neurons on the $13 \phi$ cover glass were permeabilized with $0.4 \%$ Triton X-100 for $1 \mathrm{hr}$ on 24-well plate (Corning). Cortical neurons were incubated antimicrotubule associated protein 2 (MAP-2, 1:800, Millipore) overnight at $4^{\circ} \mathrm{C}$ and then incubated with secondary antibody conjugated with Alexa 488 (1:400, Jackson Immunoresearch) at $4^{\circ} \mathrm{C}$ for $2 \mathrm{hr}$. Cortical neurons were mounted in the antifading medium Vectashield (Vector Laboratories). Images were captured with the C2si Confocal Laser Microscope (CLMS, Nikon Corporation, Tokyo, Japan) using $\times 20$ (NA: 0.75) dry lens and $\times 60($ NA: 1.4) oil immersion lens.

2.7. Analyses of Dendrite Morphology in Cortical Neurons. Bead-forming neuron was defined as the neuron that has at least one beading structure on the dendrite. The number of bead-forming neurons was counted. Bead formation was 


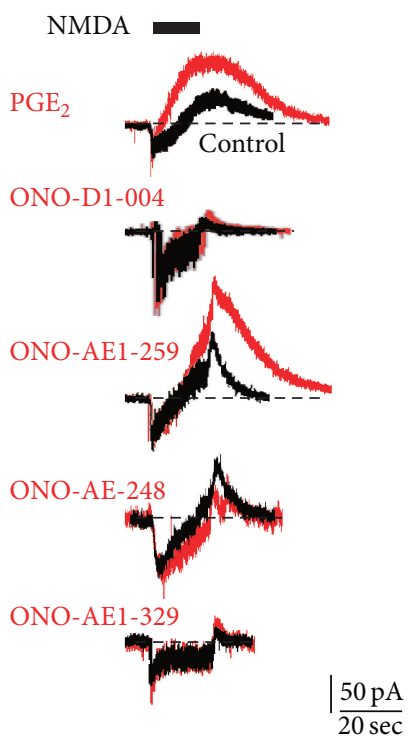

(a)

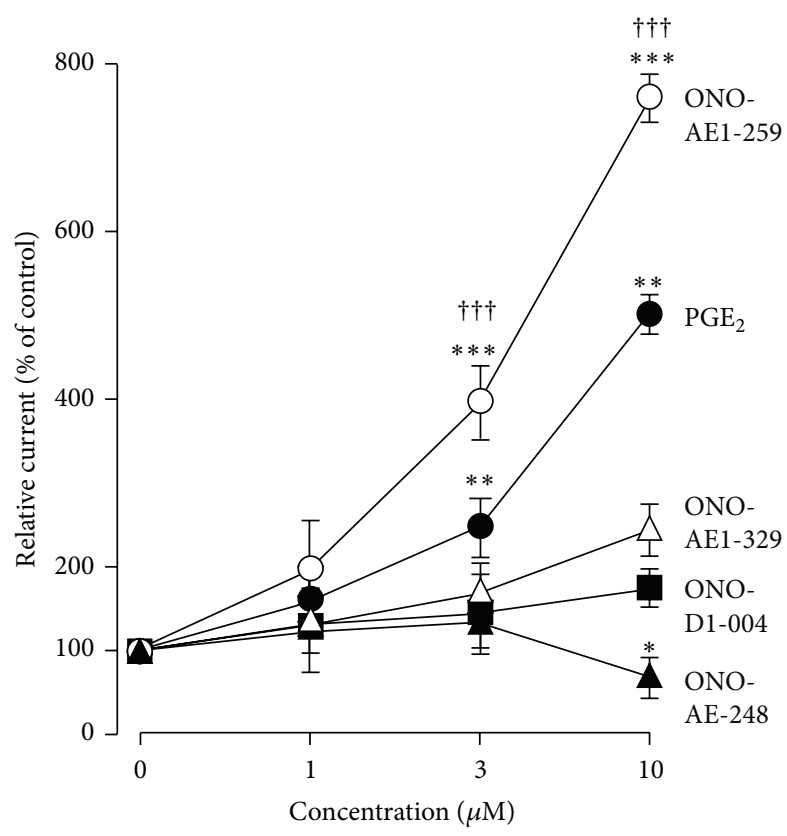

(b)

FIGURE 1: Potentiation of NMDA-induced outward currents through the activation of EP2 receptors in the acutely dissociated mouse cortical neurons. (a) Superimposed traces show NMDA-induced currents in the absence (black traces) or the presence (red traces) of drugs. PGE 2 $(10 \mu \mathrm{M}$ ), ONO-DI-004 (an EP1 receptor agonist, $10 \mu \mathrm{M}$ ), ONO-AE1-259 (an EP2 receptor agonist, $10 \mu \mathrm{M}$ ), ONO-AE-248 (an EP3 receptor agonist, $10 \mu \mathrm{M}$ ), and ONO-AE1-329 (an EP4 receptor agonist, $10 \mu \mathrm{M}$ ) were simultaneously applied with NMDA (30 $\mu \mathrm{M})$. A black line indicates the drug application period. Broken lines indicate basal currents. Calibration bars are $50 \mathrm{pA}$ and 20 sec. (b) Dose response of EP receptor agonists on NMDA-induced outward currents. The symbols and bars represent the mean \pm SEM $(n=5-7$ cells in each responses). Asterisks indicate a significant difference from $0 \mu \mathrm{M}\left({ }^{*} P<0.05,{ }^{* *} P<0.01\right.$, and ${ }^{* * *} P<0.001$, one-way ANOVA with post hoc Dunnett's test). Swords indicate a significant difference between $\mathrm{PGE}_{2}$ and ONO-AE1-259 $\left({ }^{\dagger \dagger \dagger} P<0.001, F_{1,40}=47.28\right.$, two-way ANOVA Bonferroni test).

displayed as a percentage of bead-forming neurons/total neurons in randomly captured images from 20 fields.

2.8. Data Analysis. The data are represented as the mean \pm SEM. Statistical analyses of the results were performed with one-way analysis of variance (ANOVA) with post hoc Dunnett's or Tukey's test and two-way ANOVA with Bonferroni test or unpaired $t$-test using the GraphPad Prism software package. The data met the assumptions of equal variances. Differences were considered significant with $P$ values less than 0.05 .

\section{Results}

3.1. Effects of E-Prostanoid Receptor Agonists on $I_{\text {NMDA-OUT }}$. The direct effects of four E-prostanoid receptor agonists on $I_{\text {NMDA-OUT }}$ were analyzed. Amphotericin B-perforate patchclamp recordings from acutely dissociated mouse cortical neurons were conducted to minimize the intracellular dialysis, because the activation of $\mathrm{BK}$ channels by $\mathrm{Ca}^{2+}$ influx through NMDARs is the underlying mechanism of $I_{\text {NMDA-OUT }}[12]$. PGE $_{2}$ and selective E-prostanoid receptor agonists were applied $5 \mathrm{~min}$ before and during the application of NMDA. NMDA $(30 \mu \mathrm{M})$ application for $20 \mathrm{sec}$ at the holding potential of $-40 \mathrm{mV}$ elicited inward currents $\left(I_{\text {NMDA-IN }}\right)$ and subsequent outward currents $\left(I_{\text {NMDA-OUT }}\right)$ shown in Figure 1(a), similar to our previous observations [1]. $\mathrm{PGE}_{2}(1-10 \mu \mathrm{M})$ significantly increased the mean amplitude of $I_{\text {NMDA-OUT }}$ in a dose dependent manner. ONO-AEl-259 $(1-10 \mu \mathrm{M})$, an EP2 receptor agonist, was found to mimic the effect of $\mathrm{PGE}_{2}$ (Figures 1(a) and 1(b)). It was also noted that the increasing effect of an EP2 receptor agonist on the mean amplitude of $I_{\text {NMDA-OUT }}$ was significantly stronger than that of $\mathrm{PGE}_{2}\left(P<0.001, F_{1,40}=47.28\right.$, two-way ANOVA; Figure 1(b)). In contrast, ONO-AE-248 $(10 \mu \mathrm{M})$, an EP3 receptor agonist, significantly reduced the amplitude of $I_{\text {NMDA-OUT }}(P<0.05$, one-way ANOVA with post hoc Dunnett's test; Figures 1(a) and 1(b)). On the other hand, ONO-DI-004 and ONO-AE1-329 (1-10 $\mu \mathrm{M})$, EP1 and EP4 receptors agonists, respectively, showed no significant effects on $I_{\text {NMDA-OUT }}$ (Figures 1(a) and 1(b)).

\subsection{Involvement of $c A M P / P K A$ Signaling Pathway in EP2} Agonist-Induced Potentiation of $I_{\text {NMDA-OUT. }}$. The activation of EP2 receptors stimulates cAMP synthesis, which in turn activates PKA [4]. We next ask whether EP2 receptor signaling pathways really can potentiate the amplitude of $I_{\text {NMDA-OUT }}$. To address the requirement of increased intracellular cAMP levels on the amplitude of $I_{\text {NMDA-OUT }}$, we performed intracellular application of cAMP through the patch pipette. Even in the whole-cell configuration, $I_{\mathrm{NMDA} \text {-OUT }}$ at holding potential of $-40 \mathrm{mV}$ was observed in the acutely dissociated mouse 


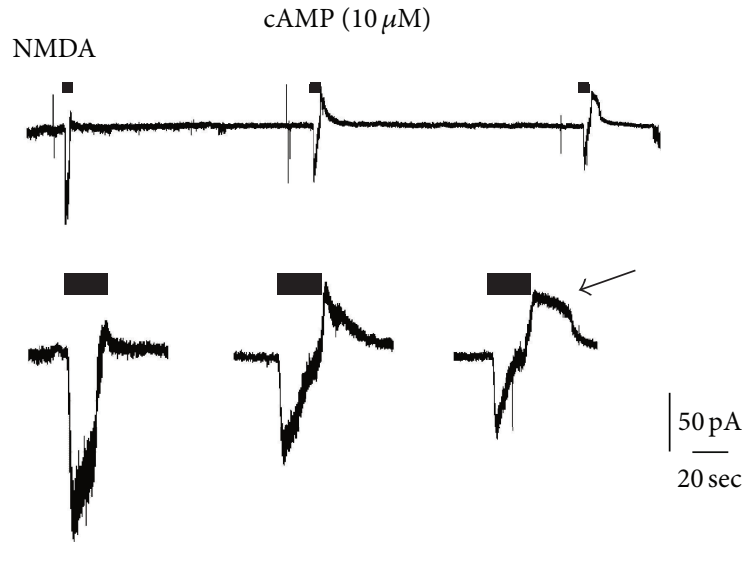

(a)

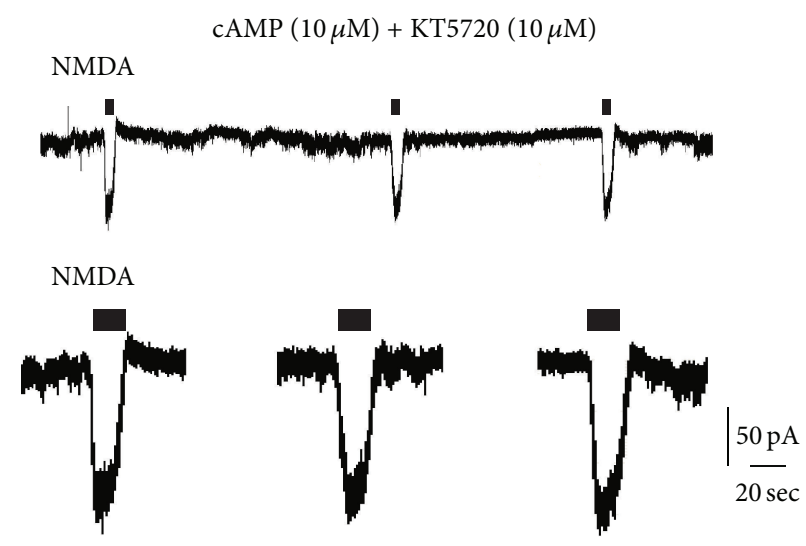

(b)

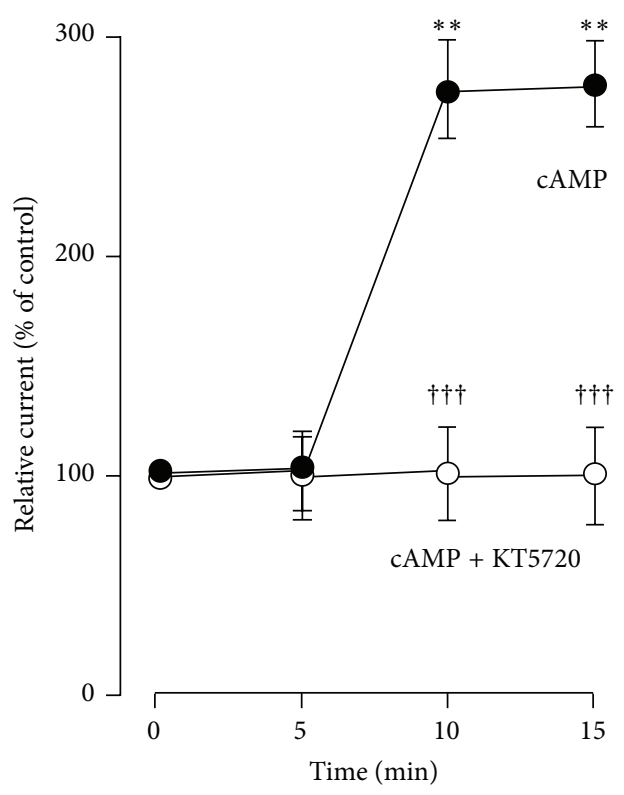

(c)

Figure 2: Cyclic AMP/PKA pathway facilitates NMDA-induced outward current in the acutely dissociated mouse cortical neurons. (a, b) Intracellular perfusion of cAMP $(10 \mu \mathrm{M})$ facilitated NMDA-induced outward currents (a), whereas KT5720 (10 $\mu \mathrm{M})$, a specific inhibitor of PKA, abolished them (b). Upper trace is continuous recording of NMDA-induced currents. Lower traces are enlarged traces of upper trace. An arrow indicates the prolonged NMDA-induced outward current. Calibration bars are $50 \mathrm{pA}$ and $20 \mathrm{sec}$ applicable to lower traces. (c) Time course of the potentiation of NMDA-induced outward currents by intracellular perfusion of cAMP. The circles and bars represent the mean $\pm \operatorname{SEM}(n=4$ cells $)$. Asterisks indicate a significant difference from the none-treated control $\left({ }^{* *} P<0.01\right.$, one-way ANOVA with post hoc Dunnett's test). Swords indicate a significant difference between cAMP and cAMP+KT5720 $\left({ }^{\dagger \dagger} P<0.01, F_{1,24}=39.32\right.$, two-way ANOVA Bonferroni test).

cortical neurons, similar to previous observations [2]. The mean amplitude of $I_{\text {NMDA-OUT }}$ was significantly increased 10 minutes after intracellular perfusion of cAMP $(10 \mu \mathrm{M})$ (Figures 2(a) and 2(c)). At the same time, the duration of $I_{\text {NMDA-OUT }}$ was markedly prolonged (Figure $2(\mathrm{a})$, an arrow). cAMP-induced increase in the amplitude and duration of $I_{\text {NMDA-OUT }}$ was completely inhibited by KT5720, a specific inhibitor of PKA (Figures 2(b) and 2(c)). We further analyzed the involvement of PKA signaling on EP2 receptor agonistsinduced potentiation of $I_{\text {NMDA-OUT }}$. To address this, we utilized distinct types of EP2 receptor agonist, ONO-AE1-259 and butaprost. An increase in the amplitude of $I_{\mathrm{NMDA}-\mathrm{OUT}}$ by EP2 receptor agonists was significantly inhibited by perfusion of KT5720 through the patch pipette (Figure 3). These results suggest that EP2 receptor signaling pathway facilitates the amplitude of $I_{\text {NMDA-OUT }}$ through PKA signaling pathway.

3.3. Facilitation of the Recovery Phase of NMDA-Induced Dendritic Beading by the Activation of EP2 Receptors. We finally examined effects of an EP2 receptor agonist on 


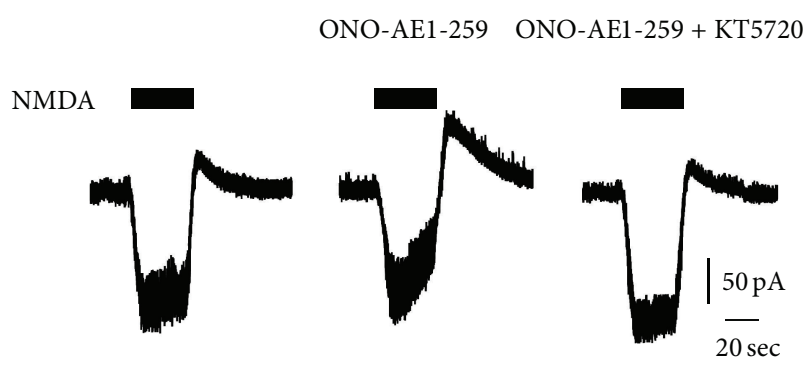

(a)

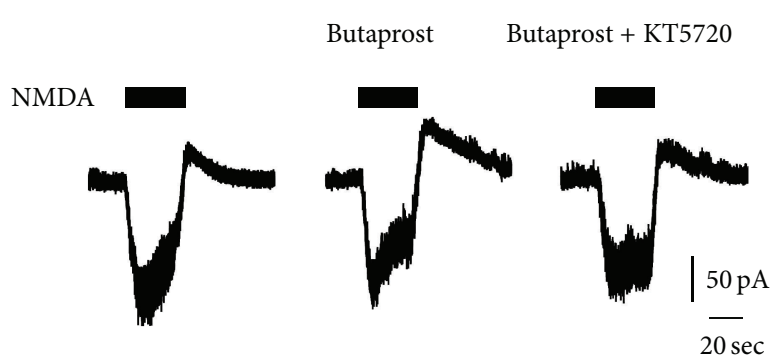

(b)

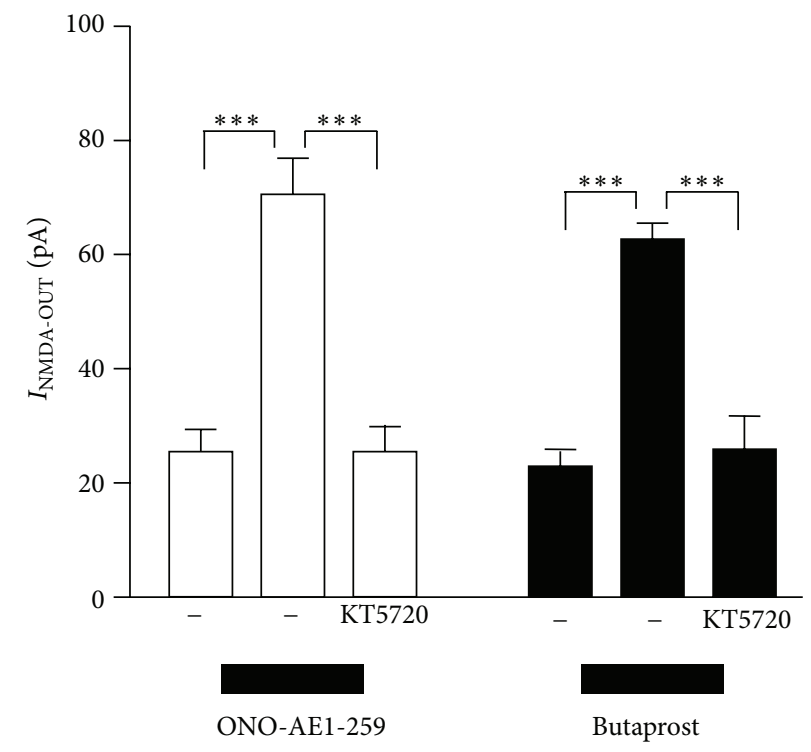

(c)

FIGURE 3: Inhibitory effects of PKA inhibitor on EP2 receptor agonists-induced potentiation of $I_{\text {NMDA-OuT }}$ (a, b) KT5720 (10 $\mu$ M) inhibited ONO-AE1-259 $(10 \mu \mathrm{M})$ or butaprost- $(10 \mu \mathrm{M})$ induced potentiation of $I_{\text {NMDA-OuT }}$. (c) Averaged amplitude of NMDA-induced outward currents. The columns and bars represent the mean \pm SEM $(n=3$ cells $)$. Asterisks indicate a significant difference between the values $\left({ }^{* * *} P<0.001\right.$, unpaired $t$-test). Calibration bars are $50 \mathrm{pA}$ and $20 \mathrm{sec}$.

NMDA-induced dendritic beading in the primary cultured mouse cortical neurons, because dendritic beading is an early morphological hallmark of excitotoxic neuronal injury. Dendritic beading leads to disappearance of dendritic spines and neurite breakage, culminating in neuronal death $[7,13$, 14]. Immunofluorescent CLMS images for MAP2 in the primary cultured cortical neurons showed that the application of NMDA $(30 \mu \mathrm{M})$ for 10 min induced the segmental focal swelling (dendritic beading) and loss of spines in the dendritic shafts (Figure 4(a)). Butaprost, an EP2 receptor agonist, partially inhibited NMDA-induced dendritic beading (Figures 4(c) and 4(d)). It is known that NMDA-induced dendrite beads disappeared completely $120 \mathrm{~min}$ after the elimination of NMDA [13]. Thus, it is possible that EP2 receptor agonistmediated neuroprotection is mainly due to the facilitation of recovery phase of NMDA-induced dendritic beading. Under the none-treated control condition, NMDA-induced dendritic beading remained even at $60 \mathrm{~min}$ after washout of NMDA (Figures 4(e) and 4(f)). When butaprost was applied with NMDA, dendritic beading was significantly recovered at $60 \mathrm{~min}$ after washout of NMDA (Figures 4(e) and 4(f)).
TG6-10-1, an EP2 receptor antagonist, significantly inhibited the butaprost-induced facilitation of recovery. We further analyzed the relationship between EP2 receptors and BK channels on neuroprotection. Paxilline, a specific BK channel blocker, also significantly abolished butaprost-induced facilitation of recovery (Figures 4(e) and 4(f)). Therefore, it is conceivable that the activation of BK channels is responsible for an EP2 agonist-induced facilitation of recovery from NMDA-induced dendritic beading.

\section{Discussion}

In the present study, an EP2 receptor agonist facilitates NMDA-induced outward currents through the activation of BK channels. cAMP/PKA signaling pathway potentiates the amplitude of $I_{\text {NMDA-OUT. }}$. Furthermore, EP2 receptor agonistmediated activation of $\mathrm{BK}$ channels promotes the recovery phase of NMDA-induced dendritic beading. Therefore, the activation of BK channels may be responsible for the neuroprotective role of EP2 receptors against excitotoxicity in cortical neurons. 


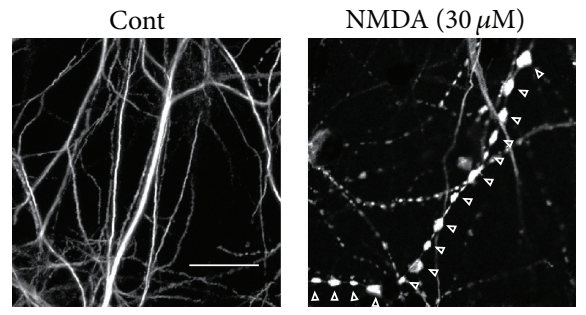

(a)

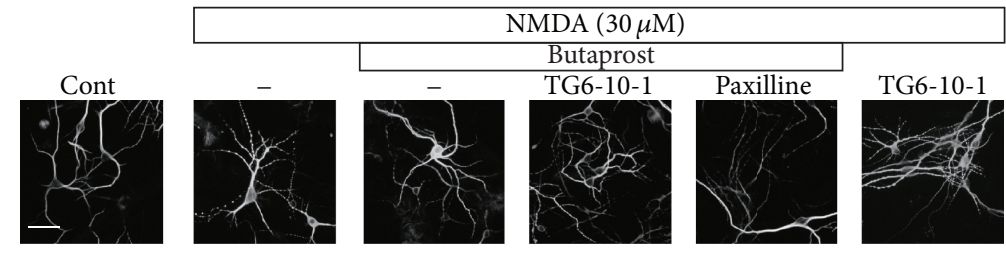

(c)

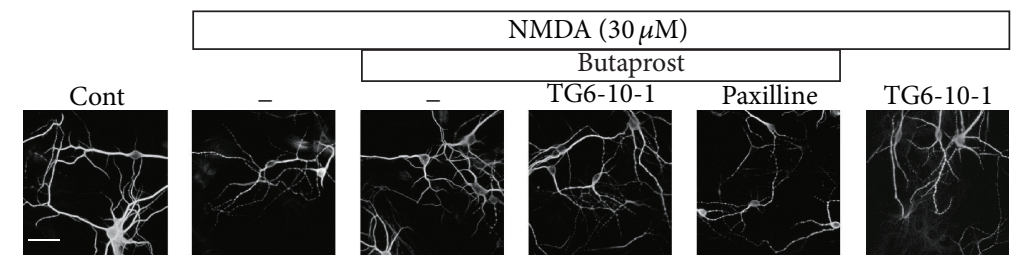

(e) (i)

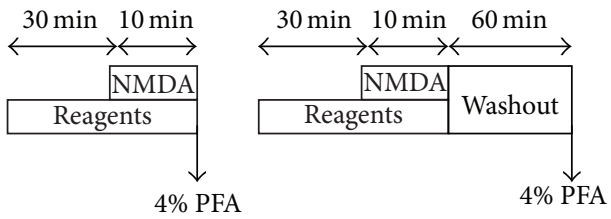

(b)

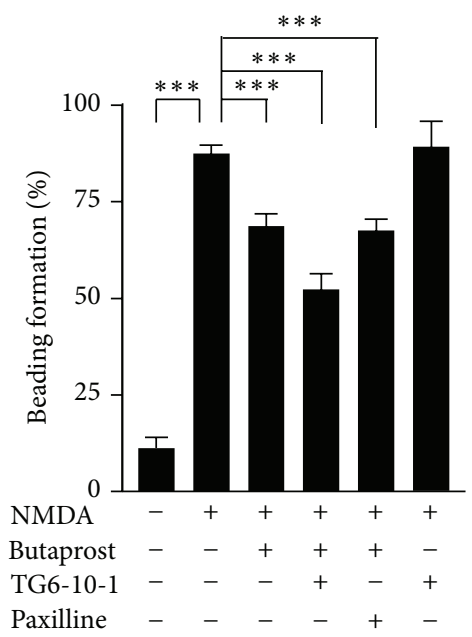

(d)

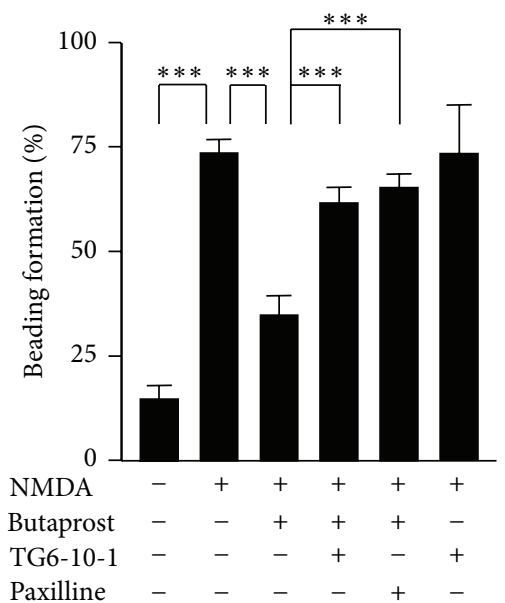

(f)

FIGURE 4: The facilitatory effects of butaprost, an EP2 receptor agonist, on the recovery phase of NMDA-induced dendritic beading through the activation of BK channels in the primary cultured mouse cortical neurons. (a) Immunofluorescent CLMS images for MAP2 in the primary cultured cortical neurons of pretreatment (left panel) or posttreatment (right panel) of NMDA $(30 \mu \mathrm{M})$ for 10 min. Arrowheads indicate beadsstructure in the dendrite. Scale bar $=20 \mu \mathrm{m}$. (b) Cortical neurons were fixed $10 \mathrm{~min}$ after the stimulation with NMDA (i) or $60 \mathrm{~min}$ after the elimination of NMDA (ii). Experimental schedules of (i) and (ii) were corresponding to (c, d) and (e, f), respectively. Data are represented as the mean \pm SEM $(n=180-235$ cells). (c, e) Immunofluorescent CLMS images for MAP2 in the primary cultured cortical neurons at 10 min after stimulation of NMDA (c) or 60 min after the elimination of NMDA (e). Butaprost (1 $\mu \mathrm{M})$, TG6-10-1 (10 $\mu \mathrm{M})$, an EP2 receptor antagonist, and paxilline $(2 \mu \mathrm{M})$ were treated 30 min before the application of NMDA. $(\mathrm{d}, \mathrm{f})$ The formation of dendritic beading of 10 min after the stimulation with NMDA (d) or 60 min after the elimination of NMDA (f). The columns and bars represent the mean \pm SEM $(n=142-173$ cells). Asterisks indicate a significant difference between the values $\left({ }^{* * *} P<0.001\right.$, one-way ANOVA post hoc Tukey' test). 
We observed distinct potency of $\mathrm{PEG}_{2}$ and ONO-AE259-01 on $I_{\text {NMDA-OUT }}$. This might be due to the distinct binding affinity for EP2 receptor. Ki value of $\mathrm{PGE}_{2}$ exhibited $12 \mathrm{nM}$ [15], whereas that of ONO-AE-259-01 was $3 \mathrm{nM}$ [16]. From the above observations, a potent effect of ONO-AE259-01 compared with $\mathrm{PGE}_{2}$ on $I_{\mathrm{NMDA}-\mathrm{OUT}}$ was reasonable. The affinity of ONO-AE-259-01 for other types of prostanoid receptors is comparatively low $(\mathrm{Ki}=140 \mathrm{nM}$ for prostaglandin $\mathrm{D}_{2}$ receptor, $\mathrm{Ki}>3.3 \times 10^{3} \mathrm{nM}$ for $\mathrm{EP} 1$ receptor, $\mathrm{EP} 3$ receptor, $\mathrm{EP} 4$ receptor, prostaglandin F receptor, prostacyclin receptor, and thromboxane receptor) [16]. Based on the binding affinity of ONO-AE-259-01, the facilitatory effect of ONO-AE-259-01 on $I_{\text {NMDA-OUT }}$ is mediated by EP2 receptors.

EP2 and EP4 receptors are involved in the intracellular increase in CAMP and subsequent activation of PKA [4]. One of the important molecular targets of PKA is the transcription factor CREB that promotes neuronal survival [9]. In fact, the protective effects of EP2 and EP4 receptor agonists on neuronal damage associated with ischemia, Alzheimer's disease, and epilepsy were reported $[5,6,17,18]$. Despite similar downstream signaling pathways of EP2 and EP4 receptors, EP4 receptors agonist had no significant effect on the amplitude of $I_{\text {NMDA-OUT }}$, suggesting a relatively low expression level of EP4 receptors in cortical neurons. These data are consistent with the region specific expression patterns of EP1 and EP4 receptors $[14,19,20]$. By contrast, EP3 receptors are broadly expressed in the cerebral cortex, hippocampus, and midbrain [21]. In the present study, we showed opposite effects of EP2 and EP3 receptor agonists on the amplitude of $I_{\text {NMDA-OUT }}$ and $\mathrm{BK}$ currents in the cortical neurons. Distinct responsiveness of EP2 and EP3 receptor agonists to $I_{\mathrm{NMDA}-\mathrm{OUT}}$ may account for the intracellular concentration of cAMP. Indeed, an EP3 receptor agonist conversely aggravates neuronal damage [22]. Thus, a local distribution pattern of EP receptor subtypes is critical for the functional outcomes of $\mathrm{PGE}_{2}$ on neurons.

Elevated levels of $\left[\mathrm{Ca}^{2+}\right]_{i}$ and the membrane depolarization [23], which serve as a feedback regulators in neurons, are known to gate the BK channels. Sensitivity of BK channels to the voltage and $\left[\mathrm{Ca}^{2+}\right]_{\mathrm{i}}$ are modulated by protein phosphorylation of serine/threonine or tyrosine residues within the channels. Generally, PKA and PKG-mediated phosphorylation lead to the activation of $\mathrm{BK}$ channels, whereas $\mathrm{PKC}$ leads to the inhibition of BK channels [24]. Inside-out mode of single channel analyses has revealed that PKA makes transition of BK channels from close-state to open-state [25]. Thus, the amplitude of $I_{\text {NMDA-OuT }}$ might be facilitated by the stimulation of EP2 receptors through the activation of PKA. The source of $\mathrm{Ca}^{2+}$ is considered as the endoplasmic reticulum (ER) or influx of extracellular calcium. Kaufmann et al. proposed that distinct route of $\mathrm{Ca}^{2+}$ activates $\mathrm{BK}$ channels [26] whose expression patterns are different from soma (clustered type) and extrasynaptic site (scattered type) [27]. The $\mathrm{Ca}^{2+}$ source of scattered type of $\mathrm{BK}$ channels might be the ER independent, whereas that of clustered type is internal stores [26]. Intriguingly, thapsigargin and ryanodine had no effect on the glutamate-evoked outward current which are mediated by BK channels [12]. From these observations, $I_{\text {NMDA-OUT }}$ caused by NMDA-application might be emerging at extrasynaptic site. This is accountable for the mechanism for the beading formation as discussed below. Beading structure was formed on the dendrite, progressing toward to soma from the tip of dendrite [28], resulting in the neuronal damage. The facilitation of recovery phase of dendritic beading by an EP2 receptor agonist was mediated by the BK channels. Therefore, extrasynaptically located BK channels might respond to an EP2 receptor agonist. Among the NMDA receptors, NR2B containing NMDA receptors are involved in the excitotoxicity [29] and located in extrasynaptic site [30]. Given the $\mathrm{Ca}^{2+}$ source and NMDA receptor's properties, scattered type of BK channels might couple to NR2B. Thus, one of potential molecular targets of $\mathrm{EP} 2$ receptor agonist is scattered type of BK channels.

EP2 receptors are widely expressed in both neurons and glia [5], whereas they exhibit opposite effects in different cells. Administration of an EP2 receptor agonist immediately after status epileptics showed neuroprotective effects [31]. In contrast, conditional deletion of EP2 receptors in microglia attenuated inflammation in animal models of Parkinson's disease or Alzheimer's disease [32, 33]. These observations indicate that EP2 receptors in microglia serve as proinflammatory signaling in the chronic neuroinflammation. Zhang et al. reported that the expression level of EP2 mRNA was increased in microglia after cellular activation [34]. In addition, autocrine/paracrine release of $\mathrm{PGE}_{2}$ further activates microglia to aggravate neuroinflammation $[32,33]$. Likewise, IL-1 $\beta$ derived from microglia also has an essential role in neuroinflammation [35-37]. Microglia specific gene-ablation of EP2 receptors results in the reduction of IL- $1 \beta$ in the hippocampus during neuroinflammatory situation [32, 33]. Secreted IL- $1 \beta$ from microglia eventually causes a loss of feedback inhibition in neurons through the attenuation of BK channel activities $[1,2]$. In this way, $\mathrm{PGE}_{2}$ and IL- $1 \beta$ synergistically worsen the pathology in chronic inflammatory situation. Taken together, the role of EP2 receptors on neuroprotection and neurodegeneration is determined by the period after the brain injury.

\section{Conclusions}

$\mathrm{PGE}_{2}$ enhanced $I_{\mathrm{NMDA}-\mathrm{OUT}}$ through the activation of EP2 receptors in mouse cortical neurons. The activation of cAMP/PKA pathway is involved in the EP2 receptor agonistinduced potentiation of $I_{\mathrm{NMDA}-\mathrm{OUT}}$. Furthermore, an EP2 receptor agonist facilitated the recovery from NMDAinduced dendritic beading. These results suggest a novel neuroprotective strategy using EP2 agonists against the acute excitotoxic damage.

\section{Competing Interests}

The authors declare no competing interests.

\section{Authors' Contributions}

Yoshinori Hayashi designed the study, performed the experiments, interpreted results, and wrote the paper. Saori Morinaga performed patch-clamp analysis and immunohistochemistry. Xia Liu performed patch-clamp analysis. Jing 
Zhang supported making primary cultured cortical neurons. Zhou Wu and Takeshi Yokoyama analyzed the data. Hiroshi Nakanishi designed the study, interpreted results, and wrote the paper. Yoshinori Hayashi and Saori Morinaga equally contributed.

\section{Acknowledgments}

The authors thank Ono Pharmaceutical Co., Ltd. (Osaka, Japan) for providing them with the prostanoid EP1-EP4 receptor agonists ONO-DI-004, ONO-AE1-259, ONO-AE248, and ONO-AE1-329. This work was supported by grants from Grants-in-Aid for Scientific Research (no. 24791979 to Yoshinori Hayashi and nos. 24390416 and $15 \mathrm{H} 05015$ to Hiroshi Nakanishi) from the Ministry of Education, Science, and Culture, Japan.

\section{References}

[1] R. Zhang, J. Yamada, Y. Hayashi, Z. Wu, S. Koyama, and H. Nakanishi, "Inhibition of NMDA-induced outward currents by interleukin- $1 \beta$ in hippocampal neurons," Biochemical and Biophysical Research Communications, vol. 372, no. 4, pp. 816820, 2008.

[2] R. Zhang, L. Sun, Y. Hayashi et al., "Acute p38-mediated inhibition of NMDA-induced outward currents in hippocampal CA1 neurons by interleukin-1 $\beta$," Neurobiology of Disease, vol. 38, no. 1, pp. 68-77, 2010.

[3] T. Katafuchi, S. Duan, S. Take, and M. Yoshimura, "Modulation of glutamate-induced outward current by prostaglandin $\mathrm{E}_{2}$ in rat dissociated preoptic neurons," Brain Research, vol. 1037, no. 1-2, pp. 180-186, 2005.

[4] Y. Sugimoto and S. Narumiya, "Prostaglandin E receptors," The Journal of Biological Chemistry, vol. 282, no. 16, pp. 11613-11617, 2007.

[5] L. McCullough, L. Wu, N. Haughey et al., "Neuroprotective function of the PGE2 EP2 receptor in cerebral ischemia," The Journal of Neuroscience, vol. 24, no. 1, pp. 257-268, 2004.

[6] J. Jiang, T. Ganesh, Y. Du et al., "Neuroprotection by selective allosteric potentiators of the EP2 prostaglandin receptor," Proceedings of the National Academy of Sciences of the United States of America, vol. 107, no. 5, pp. 2307-2312, 2010.

[7] D. Liu, L. Wu, R. Breyer, M. P. Mattson, and K. Andreasson, "Neuroprotection by the PGE2 EP2 receptor in permanent focal cerebral ischemia," Annals of Neurology, vol. 57, no. 5, pp. 758761, 2005.

[8] M. Ahmad, S. Saleem, Z. Shah, T. Maruyama, S. Narumiya, and S. Doré, "The PGE2 EP2 receptor and its selective activation are beneficial against ischemic stroke," Experimental and Translational Stroke Medicine, vol. 2, no. 1, article 12, 2010.

[9] G. E. Hardingham, Y. Fukunaga, and H. Bading, "Extrasynaptic NMDARs oppose synaptic NMDARs by triggering CREB shutoff and cell death pathways," Nature Neuroscience, vol. 5, no. 5, pp. 405-414, 2002.

[10] J. Jiang, Y. Quan, T. Ganesh, W. A. Pouliot, F. E. Dudek, and R. Dingledine, "Inhibition of the prostaglandin receptor EP2 following status epilepticus reduces delayed mortality and brain inflammation," Proceedings of the National Academy of Sciences of the United States of America, vol. 110, no. 9, pp. 3591-3596, 2013.
[11] Y. Hayashi, H. Ishibashi, K. Hashimoto, and H. Nakanishi, "Potentiation of the NMDA receptor-mediated responses through the activation of the glycine site by microglia secreting soluble factors," Glia, vol. 53, no. 6, pp. 660-668, 2006.

[12] J. S. Isaacson and G. J. Murphy, "Glutamate-mediated extrasynaptic inhibition: direct coupling of NMDA receptors to $\mathrm{Ca}^{2+}$ activated $\mathrm{K}^{+}$channels," Neuron, vol. 31, no. 6, pp. 1027-1034, 2001.

[13] M. J. Hasbani, M. L. Schlief, D. A. Fisher, and M. P. Goldberg, "Dendritic spines lost during glutamate receptor activation reemerge at original sites of synaptic contact," The Journal of Neuroscience, vol. 21, no. 7, pp. 2393-2403, 2001.

[14] J. Zhang and S. Rivest, "Distribution, regulation and colocalization of the genes encoding the $\mathrm{EP}_{2}$ - and $\mathrm{EP}_{4}-\mathrm{PGE}_{2}$ receptors in the rat brain and neuronal responses to systemic inflammation," European Journal of Neuroscience, vol. 11, no. 8, pp. 2651-2668, 1999.

[15] M. Kiriyama, F. Ushikubi, T. Kobayashi, M. Hirata, Y. Sugimoto, and S. Narumiya, "Ligand binding specificities of the eight types and subtypes of the mouse prostanoid receptors expressed in Chinese hamster ovary cells," British Journal of Pharmacology, vol. 122, no. 2, pp. 217-224, 1997.

[16] T. Saeki, T. Ota, M. Aihara, and M. Araie, "Effects of prostanoid EP agonists on mouse intraocular pressure," Investigative Ophthalmology and Visual Science, vol. 50, no. 5, pp. 2201-2208, 2009.

[17] A. Akram, C. L. Gibson, and B. D. Grubb, "Neuroprotection mediated by the $\mathrm{EP}_{4}$ receptor avoids the detrimental side effects of COX-2 inhibitors following ischaemic injury," Neuropharmacology, vol. 65, pp. 165-172, 2013.

[18] V. Echeverria, A. Clerman, and S. Doré, "Stimulation of PGE2 receptors EP2 and EP4 protects cultured neurons against oxidative stress and cell death following $\beta$-amyloid exposure," European Journal of Neuroscience, vol. 22, no. 9, pp. 2199-2206, 2005.

[19] E. Candelario-Jalil, H. Slawik, I. Ridelis et al., "Regional distribution of the prostaglandin E2 receptor EP1 in the rat brain: accumulation in Purkinje cells of the cerebellum," Journal of Molecular Neuroscience, vol. 27, no. 3, pp. 303-310, 2005.

[20] J. Zhang and S. Rivest, "A functional analysis of EP4 receptorexpressing neurons in mediating the action of prostaglandin E2 within specific nuclei of the brain in response to circulating interleukin-1 $\beta$," Journal of Neurochemistry, vol. 74, no. 5, pp. 2134-2145, 2000.

[21] T. Yamaguchi, T. Kubota, S. Watanabe, and T. Yamamoto, "Activation of brain prostanoid EP3 receptors via arachidonic acid cascade during behavioral suppression induced by $\Delta 8$ tetrahydrocannabinol," Journal of Neurochemistry, vol. 88, no. 1, pp. 148-154, 2004.

[22] Y. Ikeda-Matsuo, H. Tanji, A. Ota et al., "Microsomal prostaglandin e synthase-1 contributes to ischaemic excitotoxicity through prostaglandin E2 EP3 receptors," British Journal of Pharmacology, vol. 160, no. 4, pp. 847-859, 2010.

[23] B. P. Bean, "The action potential in mammalian central neurons," Nature Reviews Neuroscience, vol. 8, no. 6, pp. 451-465, 2007.

[24] X.-B. Zhou, I. Wulfsen, E. Utku et al., "Dual role of protein kinase C on BK channel regulation," Proceedings of the National Academy of Sciences of the United States of America, vol. 107, no. 17, pp. 8005-8010, 2010.

[25] H. A. Widmer, I. C. M. Rowe, and M. J. Shipston, "Conditional protein phosphorylation regulates $\mathrm{BK}$ channel activity in rat 
cerebellar Purkinje neurons," Journal of Physiology, vol. 552, no. 2, pp. 379-391, 2003.

[26] W. A. Kaufmann, Y. Kasugai, F. Ferraguti, and J. F. Storm, "Two distinct pools of large-conductance calcium-activated potassium channels in the somatic plasma membrane of central principal neurons," Neuroscience, vol. 169, no. 3, pp. 974-986, 2010.

[27] W. A. Kaufmann, F. Ferraguti, Y. Fukazawa et al., "Largeconductance calcium-activated potassium channels in Purkinje cell plasma membranes are clustered at sites of hypolemmal microdomains," Journal of Comparative Neurology, vol. 515, no. 2, pp. 215-230, 2009.

[28] S. M. Greenwood, S. M. Mizielinska, B. G. Frenguelli, J. Harvey, and C. N. Connolly, "Mitochondrial dysfunction and dendritic beading during neuronal toxicity," The Journal of Biological Chemistry, vol. 282, no. 36, pp. 26235-26244, 2007.

[29] Y. Liu, T. P. Wong, M. Aarts et al., "NMDA receptor subunits have differential roles in mediating excitotoxic neuronal death both in vitro and in vivo," The Journal of Neuroscience, vol. 27, no. 11, pp. 2846-2857, 2007.

[30] P. Paoletti, C. Bellone, and Q. Zhou, "NMDA receptor subunit diversity: impact on receptor properties, synaptic plasticity and disease," Nature Reviews Neuroscience, vol. 14, no. 6, pp. 383400, 2013.

[31] G. E. Serrano, N. Lelutiu, A. Rojas et al., "Ablation of cyclooxygenase-2 in forebrain neurons is neuroprotective and dampens brain inflammation after status epilepticus," The Journal of Neuroscience, vol. 31, no. 42, pp. 14850-14860, 2011.

[32] J. U. Johansson, S. Pradhan, L. A. Lokteva et al., "Suppression of inflammation with conditional deletion of the prostaglandin $\mathrm{E}_{2}$ $\mathrm{EP}_{2}$ receptor in macrophages and brain microglia," The Journal of Neuroscience, vol. 33, no. 40, pp. 16016-16032, 2013.

[33] J. U. Johansson, N. S. Woodling, Q. Wang et al., "Prostaglandin signaling suppresses beneficial microglial function in Alzheimer's disease models," The Journal of Clinical Investigation, vol. 125, no. 1, pp. 350-364, 2015.

[34] T. Zhang, X. Gong, G. Hu, and X. Wang, "EP2-PKA signaling is suppressed by triptolide in lipopolysaccharide-induced microglia activation," Journal of Neuroinflammation, vol. 12, no. 1, article 50, 2015.

[35] K. Terada, J. Yamada, Y. Hayashi et al., "Involvement of cathepsin B in the processing and secretion of interleukin- $1 \beta$ in chromogranin a-stimulated microglia," Glia, vol. 58, no. 1, pp. $114-124,2010$.

[36] X. Sun, D. Zhou, P. Zhang, E. G. Moczydlowski, and G. G. Haddad, " $\beta$-subunit-dependent modulation of hSlo BK current by arachidonic acid," Journal of Neurophysiology, vol. 97, no. 1, pp. 62-69, 2007.

[37] Y. Hayashi, M. Yoshida, M. Yamato et al., "Reverse of agedependent memory impairment and mitochondrial DNA damage in microglia by an overexpression of human mitochondrial transcription factor A in mice," The Journal of Neuroscience, vol. 28, no. 34, pp. 8624-8634, 2008. 


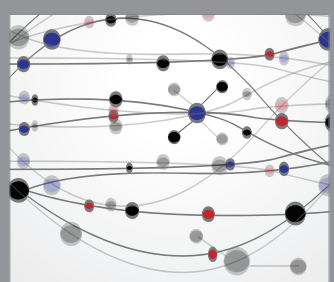

The Scientific World Journal
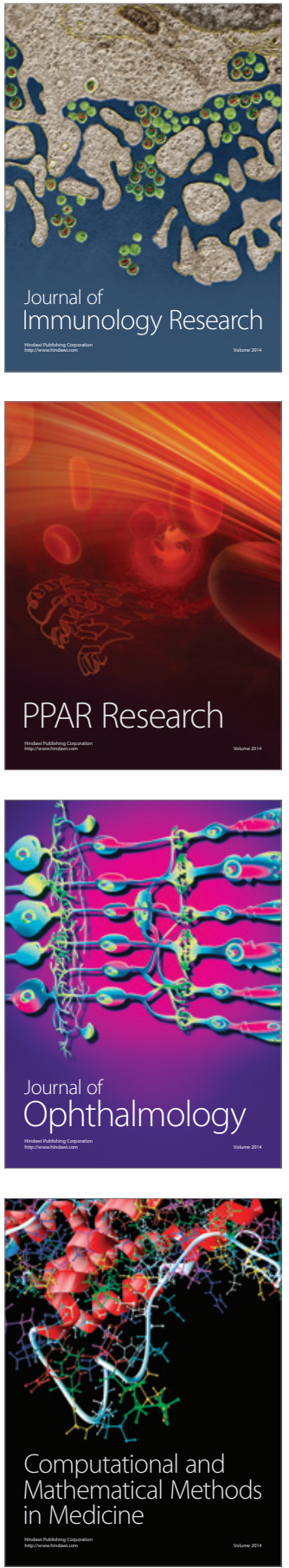

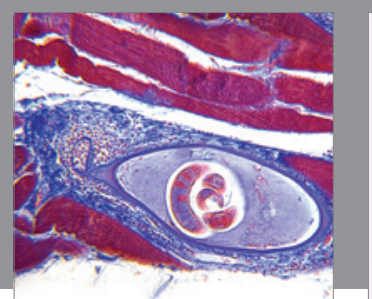

Gastroenterology Research and Practice

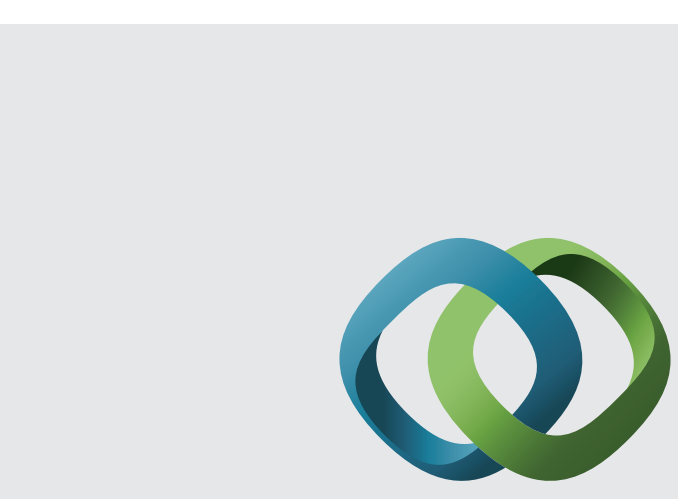

\section{Hindawi}

Submit your manuscripts at

http://www.hindawi.com
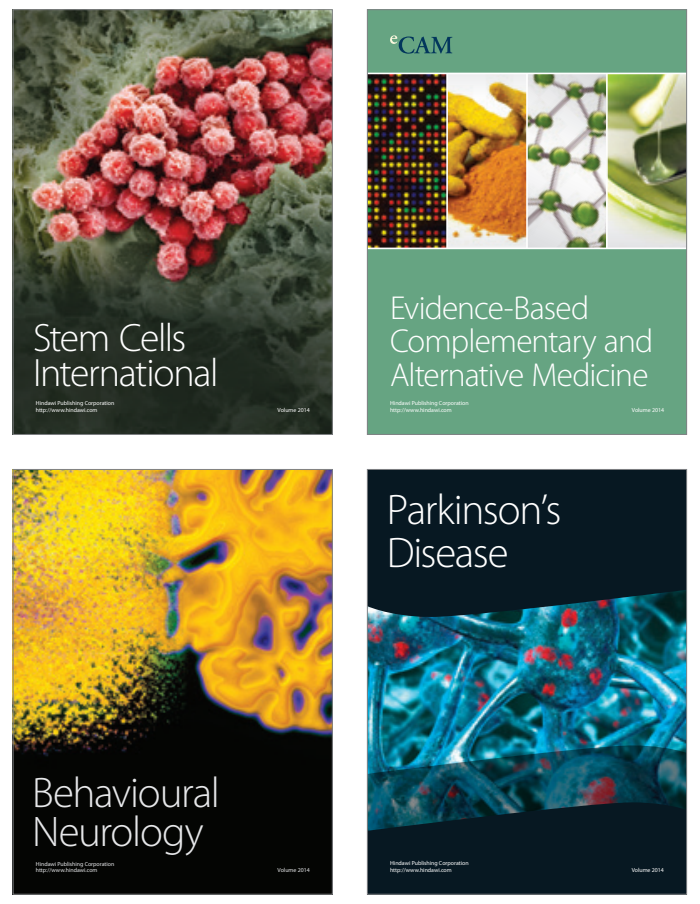
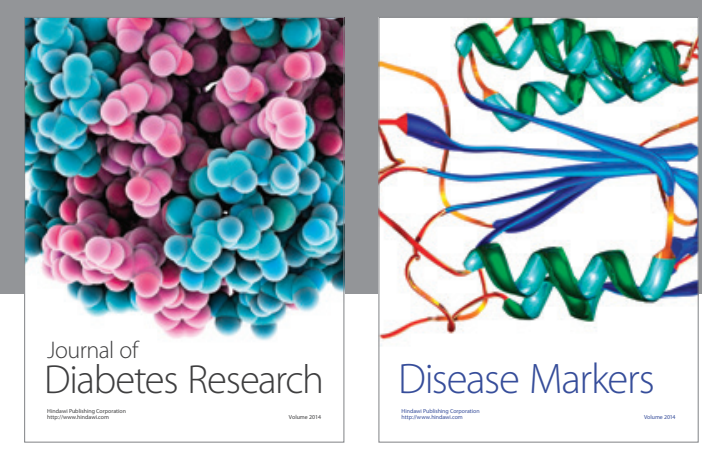

Disease Markers
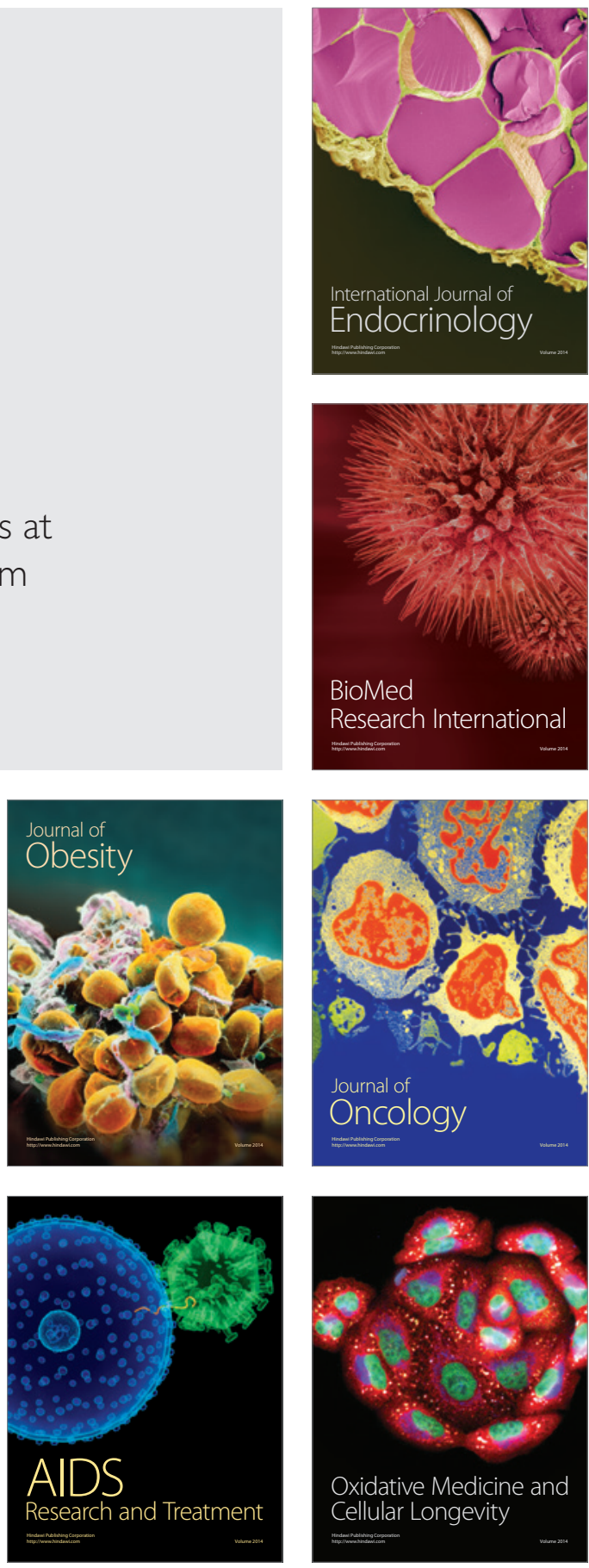